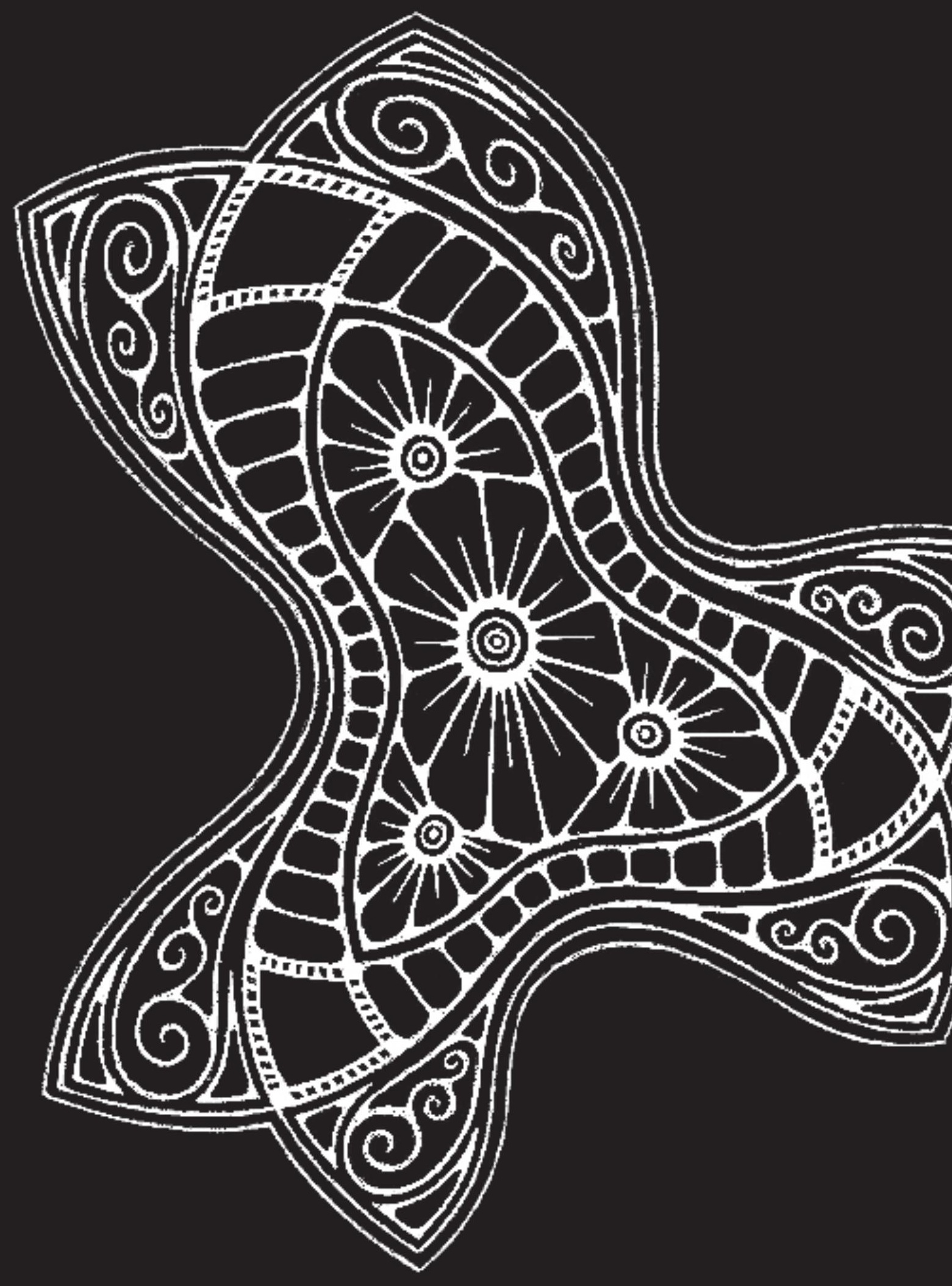




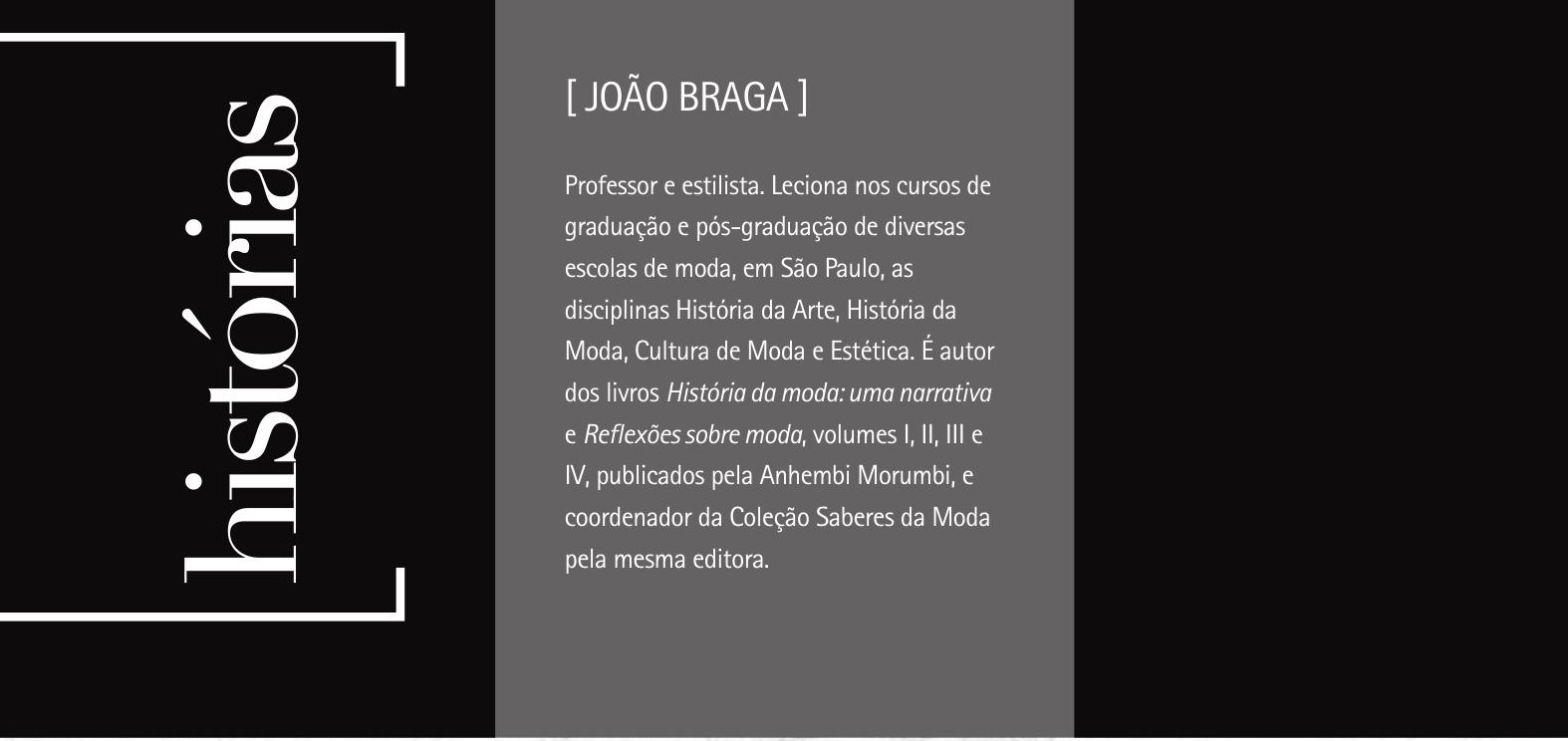

Aristocrata francesa escolhe tecidos no ateliê de Rose Bertin

Fonte: COSGRAVE, Bronwyn. Historia de la moda: desde Egipto hasta nuestros dias. Barcelona: Gustavo Gili, 2005, p. 170.

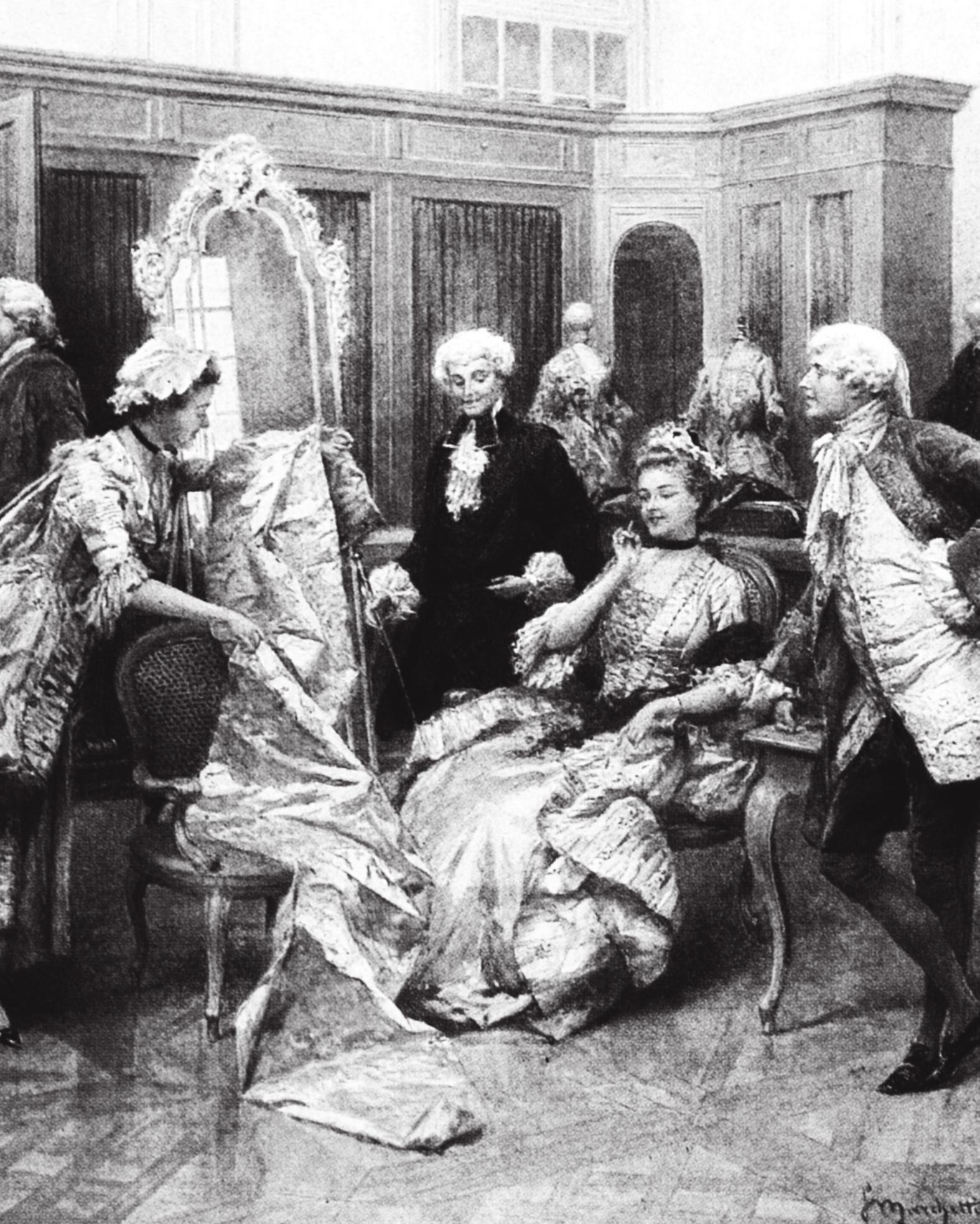




\section{Rose Bertin}

Este breve relato é uma homenagem pessoal ao Ano da França no Brasil, celebrado em 2009 em retribuição ao Ano do Brasil na França (2005).

Um dos patrimônios culturais franceses, entre inúmeros outros, é a moda. Conhecida e reconhecida mundialmente, a moda francesa tem uma longa e grande tradição que remonta não somente, mas especialmente, ao tempo do Barroco, quando Luís XIV determina e estabelece uma conduta que trouxe para a França prestígio em diversas áreas, como a moda. Com os três últimos Luíses, o período denominado Ancien Règime determina regras, condutas e posturas que vão servir de exemplo civilizador para o restante do mundo.

Poder-se-ia fazer um histórico da moda francesa dos períodos Barroco e Rococó, mas não é o caso. Neste momento, meu objetivo é retratar e divulgar em Terra Brasilis um grande nome da moda francesa pouco conhecido pelos brasileiros. Trata-se de uma mulher pioneira no que diz respeito à prática de ao que hoje chamamos pesquisa e criação de moda, além dos aspectos de domínio técnico, negócios, divulgação e consequente prestígio social advindos do universo das roupas. Ela foi grande modista a seu tempo, precursora do costureiro parisiense e também do dito "comércio das aparências". Refiro-me à Mademoiselle Bertin.

Rose Bertin Marie-Jeanne, também conhecida como Mademoiselle Bertin, Rose Bertin ou somente Rose, nasceu em Amiens em 1744 numa família modesta. Aos 23 anos, mudou-se para Paris, mas mesmo antes de chegar à capital francesa já conhecia e praticava o ofício de costureira, aprendido com Mademoiselle Barbier na cidade de Abbeville.

Ao estabelecer-se na capital, fundou seu próprio negócio de moda em 24 de outubro de 1773, uma butique denominada Grand Mogol, situada à rua Saint-Honoré. Acredita-se que o nome de sua loja seja referência ao famoso diamante "Grão Mogol" - hoje desaparecido - encontrado, em 1640, nas minas de Sallur, Índia. Esse diamante recebeu o nome em homenagem a Shah Jahan (1628-1658), imperador indiano da dinastia Mogol, que construiu o Taj Mahal como prova de amor à sua esposa.

0 andar térreo da loja atraía uma enorme clientela não só pela agradável decoração como, essencialmente, pelas toilettes criadas por Rose, que eram exibidas ao público francês em bonecas-manequim antes de partir para outros países europeus. Em seu ateliê, Mademoiselle Bertin empregava uma trintena de hábeis e dedicadas funcionárias sob a chefia de sua contramestra (la première) Mademoiselle Vêchard. Essas bonecas-manequim partiam mensalmente de Paris, vestidas em miniaturas das últimas novidades criadas por Mademoiselle Bertin, para outras cortes europeias - primeiramente a inglesa - a fim de servir de porta-voz da moda francesa no estrangeiro, considerada superior tanto técnica quanto esteticamente.

Seu sucesso era tamanho que logo foi descoberta pela duquesa de Chartres e daí foi um passo para chegar também às graças da rainha Maria Antonieta (1755-1793). Essa pequena austríaca havia sido escolhida para casar-se com o delfim de França, o futuro Luís XVI. De pele clara e cabelos louros, Maria Antonieta casou-se à idade de 15 e tornou-se rainha em 1774. Foi a última rainha dos franceses e deixou um legado de modo de vida e estilo próprios que influenciou contemporâneos por seu temperamento, seu espírito independente, suas sutilezas e, principalmente, por suas frivolidades. Feminina e glamourosa, Maria Antonieta tornou-se referência incontestável de moda, e não há dúvidas de que muito dessa realidade estava sob os auspícios de Mademoiselle Bertin.

Maria Antonieta fez de Rose Bertin sua conselheira preferida e particular, sendo a única fornecedora da rainha que tinha autorização para penetrar na intimidade de Sua Majestade. Apresentava-se semanalmente à rainha e para maiores facilidades chegou a alugar um apartamento em Versalhes. Não foi de admirar que acabou recebendo de seus inimigos a alcunha de "ministra de modas da rainha Maria Antonieta". Todavia, independente de qualquer coisa, Rose Bertin tornou-se a grande criadora de roupas e penteados durante o reinado de Luís XVI.

Ditou verdadeiramente moda e, em sua loja em Paris, mais do que roupas, apresentava também propostas para penteados, chapéus, joias e sapatos, estes normalmente 
bordados com pedrarias. Também criou roupas infantis e roupas próprias para caçadas. Utilizava, entre outros tecidos, especialmente gazes de lã, crepe, cetim e organdi. Ao se tornar fornecedora da rainha, grande parte da criação de Rose Bertin destinou-se à glorificação da monarquia francesa, especialmente com os denominados grands habits (grandes hábitos ou roupas); porém, também criou os trajes do dia a dia da corte de acordo com as necessidades da época. $E$, por incrivel que pareça, fez inúmeros vestidos de noiva, tanto para francesas quanto para a clientela estrangeira.

Rose costumava dar nomes aos estilos de seus vestidos e os denominava de vestidos à francesa, vestidos à muçulmana, vestidos à sultana, vestidos à maneira de Pequim, vestidos de uniforme, vestidos à polonesa, vestidos à inglesa, vestidos à grega e, evidentemente, os também vestidos-camisa.

Percebam o quanto Rose Bertin pesquisava a indumentária histórica para seu processo criativo, o que hoje no universo da moda ainda é comum. Essa moda de Rose Bertin tornou-se muito marcante nas décadas de 1770 e 1780, conhecida como a explosão da moda rococó, que coincide com os períodos da implantação de sua loja (1773) e da coroação de Maria Antonieta (1774).

Além do enorme talento para conhecer e trabalhar tecidos, Rose Bertin dava nome às cores, fazia álbuns com amostras dos tecidos e sugeria penteados. Os adornos de cabeça eram significativos no comércio de moda de Mademoiselle Bertin. Seus desenhos e sugestões de penteados pouf foram tão famosos quanto suas toucas e chapéus. Esses penteados que a história da moda conheceu durante 0 reinado de Luís $\mathrm{XVI}$, na maioria das vezes, não só nos encantam como também causam admiração e espanto e costumam ser adjetivados de pitorescos, burlescos, extravagantes e alucinantes.

Com toda essa dedicação e esmero, Rose Bertin, com seus trabalhos de moda, teve uma enorme reputação em toda a Europa, fundamentalmente por ter se tornado a criadora de moda - àquele tempo dizia-se "modista" - preferida da rainha Maria Antonieta.

Não resta dúvida de que a Revolução Francesa também modificou o destino de Mademoiselle Bertin. Pouco tempo antes da Queda da Bastilha, em 14 de julho de 1789, já havia se estabelecido no número 26 da rua Richilieu.

Morreu em Paris no ano de 1813 e, merecidamente, a história da moda a reconhece como uma grande precursora dos valores e denominações desse universo. Verdadeiro arauto de como futuramente os profissionais de moda seriam chamados de "costureiro" (a partir de 1857/1858), de "estilista" (a partir dos anos 1960) e de personal stylist (a partir do final do século XX).

Como os vestidos a seu tempo não costumavam ser assinados, torna-se difícil encontrar e comprovar uma roupa de sua criação. Uma das que se credita à sua autoria é um vestido de cauda de 1780 que pertenceu à Maria Antonieta e hoje está no Royal Ontario Museum, em Toronto, no Canadá.

\section{SAIBA MAIS}

GOETZ, Adrien. Le style Marie-Antoinette. Paris: Assouline, 2005.

ROCHE, Daniel. A cultura das aparências: uma história da indumentária (séculos XVII-XVIII). São Paulo: Senac, 2009.

SAPORI, Michelle. Rose Bertin: ministre des modes de Marie-Antoinette. Paris: Regard Institute Français de la Mode, 2003.

WEBER, Caroline. A rainha da moda: como Maria Antonieta se vestiu para a Revolução.

Rio de Janeiro: Jorge Zahar, 2008. 